\title{
Long term domiciliary oxygen treatment for chronic respiratory failure reviewed
}

\author{
S V Baudouin, J C Waterhouse, T Tahtamouni, J A Smith, J Baxter, P Howard
}

\begin{abstract}
The use of long term domiciliary oxygen therapy in the Sheffield area from June to August 1987 has been surveyed. Of the 74 patients prescribed long term domiciliary oxygen therapy, 64 were visited at home. These had arterial blood gas tensions or oxygen saturation measured (while breathing oxygen and air), and the indications for long term domiciliary oxygen therapy were examined retrospectively. Fifty two patients had chronic bronchitis and emphysema, the remainder having pneumoconiosis, bronchiectasis, fibrosing alveolitis, and congestive cardiac failure. Of the 54 cases where indications for treatment could be compared with the Department of Health and Social Security (DHSS) guidelines, only $23(43 \%)$ met the full DHSS criteria before the start of treatment. The median length of treatment was 16 months. At follow up 51 patients had an arterial oxygen tension $\left(\mathrm{PaO}_{2}\right)$ greater than $8 \cdot 0$ kPa when breathing oxygen. They had a significantly higher $\mathrm{PaO}_{2}$ when breathing air than before long term oxygen therapy (6.7 (SD 1.2) $\mathrm{kPa}$ before oxygen treatment, $7.6(1 \cdot 4) \mathrm{kPa}$ on reassessment). A similar change was seen in the 23 patients assessed as recommended by the DHSS $(6.1(0.8) \mathrm{kPa}$; $7.2(1.2)) . \mathrm{PaO}_{2}$ during the breathing of air was less than $7 \cdot 3 \mathrm{kPa}$ at reassessment in only $21(33 \%)$ patients. Thirteen patients had carboxyhaemoglobin concentrations above $2 \cdot 5 \%$, the 95th centile of the distribution in nonsmokers in the laboratory.
\end{abstract}

In the early 1980 s two large, randomised trials showed that long term oxygen therapy improved survival in patients with cor pulmonale. ${ }^{12}$ These findings have posed both economic and logistic problems in terms of financing and supplying home oxygen therapy, and in Great Britain the Department of Health and Social Security (DHSS; now the Department of Health) issued guidelines ${ }^{34}$ in an attempt to ensure that treatment is prescribed appropriately.

Patients have been assumed to require long term oxygen therapy for life. The possibility that improvement could occur has not been studied. Patients in Sheffield having long term oxygen therapy have been reviewed to see whether they met the DHSS criteria. Patients were reassessed at home, with measurements of arterial oxygenation, and the indications for treatment were studied retrospectively.

\section{Methods}

The DHSS has published criteria for prescribing long term oxygen therapy. ${ }^{3}$ These state that patients should fall into one of three diagnostic groups-namely, cor pulmonale, hypoxic chronic bronchitis and emphysema, or hypoxic lung disease requiring palliation. The patient should be stable when assessed, and have $\mathrm{a} \mathrm{PaO}_{2}$ less than $7.3 \mathrm{kPA}$ and $\mathrm{a} \mathrm{PaCO}_{2}$ greater than $6.0 \mathrm{kPa}$ on two occasions at least three weeks apart. $\mathrm{FEV}_{1}$ should be less than 1.5 litres. The patient should preferably have seen a chest physician.

Patients using oxygen concentrators prescribed by general practitioners in the Sheffield and Rotherham areas in Spring 1987 were identified from the records of the Family Practitioner Committees. Seventy four such patients were identified, and 64 of these were visited at home. Permission was obtained from both the patient and the general practitioner before a home visit. During the visit an arterial blood gas sample was taken into a heparinised syringe and stored in ice. Oxygen saturation $\left(\mathrm{SaO}_{2}\right)$ was recorded simultaneously from an ear oximeter (Ohmeda Biox 3700 oximeter). The arterial sample was analysed (Corning 170 analyser) within three hours of being taken. The Corning 170 has a self calibrating, self cleaning mode. Independent calibrations were performed regularly by means of the Ciba Corning "Certain" three level system. Haemoglobin and carboxyhaemoglobin concentrations were measured by spectrophotometry (IL-152 Instrumentation Ltd) with the inbuilt calibration system. We have taken $2.5 \%$ to be the upper limit of carboxyhaemoglobin in non-smokers, this value being the upper 95th percentile of the carboxyhaemoglobin distribution from a study of 30 declared non-smokers from our laboratory (unpublished data).

Thirty patients were breathing oxygen when the team arrived. After the first recording of oxygen saturation patients were asked to change the gas they were breathing (oxygen to air or air to oxygen) for at least 20 minutes, and oxygen saturation was again recorded. Arterial oxygen tension was calculated from measured oxygen saturation on the assumption of a constant $\left[\mathrm{H}^{+}\right]$and base excess derived from a standard line chart. ${ }^{5}$ A comparison of oxygen saturation calculated from arterial $\mathrm{Po}_{2}$ and the values obtained by oximetry was made for the 30 patients initially breathing room air. Agreement to within $4 \%$ was achieved in 21 of the 30 readings (range of difference $0-7 \%$ ). Arterial oxygen saturation derived from $\mathrm{PaO}_{2}$ was on average 3\% higher than $\mathrm{SaO}_{2}$ recorded by oximetry. FEV and FVC were measured
Dr P How reprint

of Medicine, Royal

Hallamshire Hospital

Sheffield S10 2JF.

Accepted 24 November 1989 
Arterial oxygen tensions $\left(\mathrm{PaO}_{2}\right)$ for 52 patients breathing air before long term oxygen therapy and at reassessment. Mean values (with 1 SEM- I) for $\mathrm{PaO}$, before treatment and at reassessment are shown. The broken line indicates the $\mathrm{PaO}_{2}$ recommended by the Department of Health and Social Security as a criterion for starting long term oxygen therapy.
Table 1 Spirometric values, arterial oxygen and carbon dioxide tensions ( $\left.\mathrm{PaO}_{2}, \mathrm{PaCO}_{2}\right)$, packed cell volume, and carboxyhaemoglobin concentration (mean (SD) values) for patients reassessed at home

\begin{tabular}{|c|c|c|}
\hline & $n$ & \\
\hline Age (y) & 64 & $\begin{array}{l}67(9) \text {, range } \\
51-86\end{array}$ \\
\hline $\begin{array}{l}\text { Male:female } \\
\text { FEV }_{1}(1) \\
\text { Forced vital capacity (1) } \\
\text { PaO, (breathing air) before oxygen }^{\text {a }} \text {, }\end{array}$ & $\begin{array}{l}64 \\
63 \\
63\end{array}$ & $\begin{array}{l}41: 23 \\
0.64(0.29) \\
1.29(0.61)\end{array}$ \\
\hline $\begin{array}{l}\text { therapy (kPa) } \\
\mathrm{PaO}_{2} \text { (breathing air) at follow up (kPa) } \\
\mathrm{PaO}_{2} \text { (breathing oxygen) at follow up }(\mathrm{kPa}) \\
\mathrm{PaCO}_{2} \text { (breathing oxygen) at }\end{array}$ & $\begin{array}{l}52 \\
52 \\
61\end{array}$ & $\begin{array}{l}6.7(1.2) \\
7.6(1.4) \\
9.0(1.9)\end{array}$ \\
\hline $\begin{array}{l}\text { follow up }(\mathrm{kPa}) \\
\text { Packed cell volume } \\
\text { Carboxyhaemoglobin }(\%)\end{array}$ & $\begin{array}{l}30 \\
54 \\
50\end{array}$ & $\begin{array}{l}7 \cdot 1(1.5) \\
0.42(0.06) \\
2 \cdot 6(1.9)\end{array}$ \\
\hline
\end{tabular}

and the flow rate and oxygen concentration delivered by the oxygen concentrator checked.

Indications for long term oxygen therapy were assessed retrospectively from inpatient notes when available. Mean arterial blood gas tensions at follow up (during air and oxygen breathing) were calculated by combining values obtained by direct measurement with those calculated from the oximeter $\mathrm{SaO}_{2}$ value. Mean arterial blood gases recorded before oxygen therapy in hospital records were compared with the values obtained at the home assessment. Where more than one set of blood gas analyses had been recorded before long

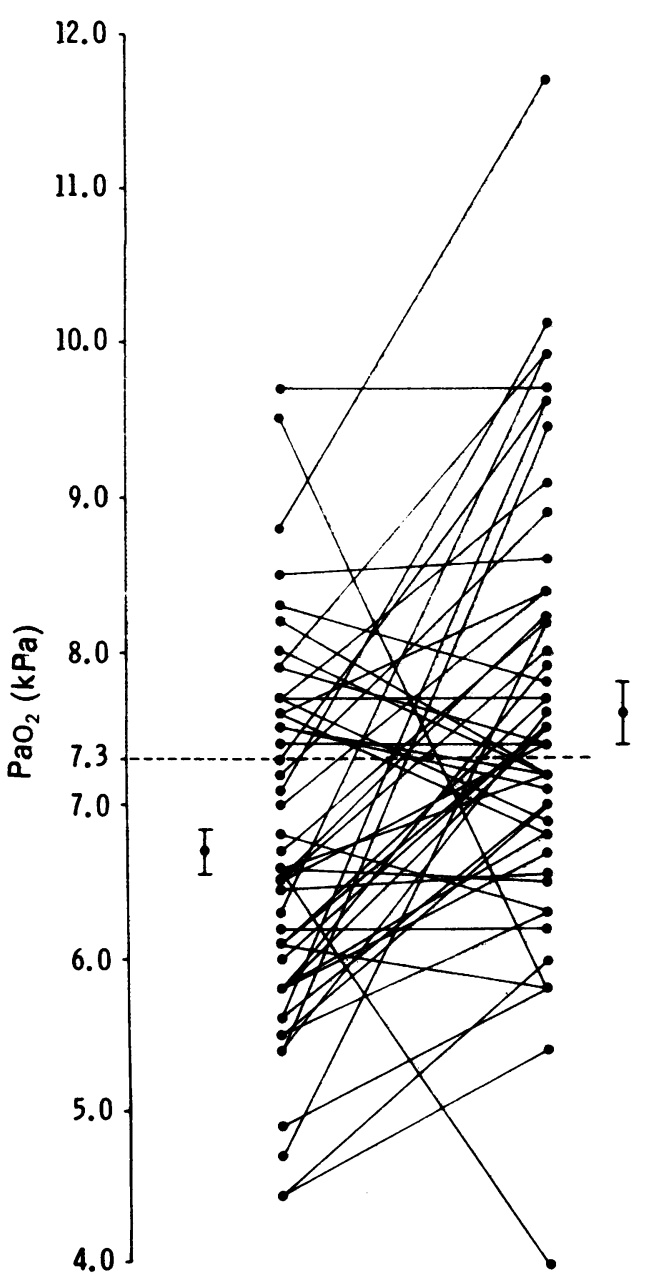

Pre-LTOT $\underset{p}{\mathrm{p}<0.001}$ Reassessment
.
Table 2 The underlying respiratory disorders leading to the prescription of long term domiciliary oxygen therapy in the 64 patients reassessed at home

\begin{tabular}{lc}
\hline Respiratory disorder & No of patients \\
\hline Chronic bronchitis and emphysema & 52 \\
Pneumoconiosis & 3 \\
Bronchiectasis & 3 \\
Fibrosing alveolitis & 2 \\
Congestive cardiac failure & 1 \\
Unknown & 3 \\
\hline
\end{tabular}

term oxygen therapy (as recommended by the Department of Health) the mean value was used.

\section{Results}

\section{DETAILS OF THE PATIENTS}

Ten of the 74 patients given long term oxygen therapy were not included in the study. Of these, three had died, two were in hospital, one was no longer receiving oxygen therapy, three had moved or could not be found, and one refused a visit. Age, sex ratio, and the results of spirometry and blood gas analysis for the 64 patients reassessed at home are presented in table 1 . The respiratory disorders leading to the prescription of long term oxygen therapy are shown in table 2 .

\section{MEETING THE DHSS CRITERIA}

We were able to assess the extent to which 54 of the 64 patients had met the DHSS criteria. Thirty two patients had been assessed as recommended, with repeated blood gas measurements. Nine of these patients had a $\mathrm{PaO}_{2}$ above $7.3 \mathrm{kPa}$, however, so only $23(43 \%)$ of the patients met all the DHSS criteria before starting treatment.

Forty one patients were in category 1 (cor pulmonale), four in category 2 (hypoxic chronic bronchitis), and nine in category 3 (palliation). Forty seven patients $(74 \%)$ were being followed up by a chest physician.

\section{CONCENTRATOR FUNCTION AND USAGE}

For most concentrators the flow rate and oxygen concentrations were reasonably accurate (table 3 ). Ten machines had a flow rate more than $200 \mathrm{ml} / \mathrm{min}$ outside the set rate (mostly $21 / \mathrm{min}$ ). Six delivered an oxygen concentration of less than $90 \%$; as expected, these included all three machines set to deliver 3 $1 /$ min or more. We could not check on the daily use of oxygen by the patients but 34 reported that they used it at least 15 hours a day. Five said that they had never been advised on the recommended daily duration of treatment.

\section{EFFECT OF TREATMENT}

The median length of treatment was 16 (range 4-117) months. In most patients satisfactory $\mathrm{PaO}_{2}$ values were found while they were breathing oxygen (mean 9.0 (SD 1.9) $\mathrm{kPa} ; \mathrm{n}=61$ ). In 13 the $\mathrm{PaO}_{2}$ was less than $8.0 \mathrm{kPa}$ while they were breathing oxygen at reassessment. The mean packed cell volume was $0.42(0.06)$. Some patients had been transferred from oxygen cylinders to concentrators when these were introduced.

A comparison of $\mathrm{PaO}_{2}$ in 52 patients breathing air before and during long term oxygen 
Table 3 Flow rates and oxygen concentrations delivered by the home oxygen concentrators

\begin{tabular}{llll}
\hline $\begin{array}{l}\text { Set flow } \\
(l / \text { min) }\end{array}$ & $\begin{array}{l}\text { No of } \\
\text { patients }\end{array}$ & $\begin{array}{l}\text { Measured flow } \\
(\text { mean }(\text { range }), l / \text { min) }\end{array}$ & $\begin{array}{l}\text { Mean concentration } \\
(\text { mean }(\text { range }), \%)\end{array}$ \\
\hline 1 & 16 & $0.81(0.63-1 \cdot 00)$ & $94(87-97)$ \\
1.5 & 5 & $1.47(1 \cdot 25-1 \cdot 60)$ & $96(95-97)$ \\
2 & 39 & $2 \cdot 27(1 \cdot 15-2 \cdot 50)$ & $94(88-97)$ \\
2.5 & 1 & 2.55 & 96 \\
3 & 2 & $2 \cdot 82(2 \cdot 75-2 \cdot 90)$ & $87(83-91)$ \\
4 & 1 & 3.95 & 80 \\
\hline
\end{tabular}

therapy showed an improvement in $\mathrm{PaO}_{2}$ from $6.7(\mathrm{SD} \mathrm{1.2})$ to $7.6(1.4) \mathrm{kPa}(\mathrm{p}<0.001$; figure). This improvement was still seen in a separate analysis confined to the 23 patients who had been assessed as recommended in the DHSS guidelines (stable with two estimations of arterial gas tensions performed at least three weeks apart). In these patients $\mathrm{PaO}_{2}$ had increased from 6.1 (SD 0.8 ) to $7 \cdot 2(1.2) \mathrm{kPa}$ $(\mathrm{p}<0.01)$ when they were breathing air. At reassessment only $21(33 \%)$ of the 64 patients receiving long term oxygen therapy had a $\mathrm{PaO}_{2}$ of less than $7 \cdot 3 \mathrm{kPa}$.

Carbon dioxide retention sufficient to be important did not occur during oxygen therapy in most patients (mean $\mathrm{PaCO}_{2}$ during oxygen breathing $7 \cdot 1(\mathrm{SD} 1 \cdot 5) \mathrm{kPa} ; \mathrm{n}=30)$, though seven patients had a $\mathrm{PaCO}_{2}$ of $7 \cdot 0 \mathrm{kPa}$ or greater. Nineteen patients who had been assessed as recommended were breathing air when the home assessment team arrived. In these patients the directly measured $\mathrm{PaO}_{2}$ improved from $6.2(0.9)$ to $7.7(1.3) \mathrm{kPa}(\mathrm{p}<0.001)$ whereas $\mathrm{PaCO}_{2}$ did not change appreciably (before long term oxygen therapy $6.8(1.0) \mathrm{kPa}$, at follow up $6.9(1.4) \mathrm{kPa}$ ).

\section{CARBOXYHAEMOGLOBIN CONCENTRATIONS}

The mean carboxyhaemoglobin concentration was $2.6 \%$ (SD $1.9 \%$ ). In 13 patients it was greater than $2.5 \%$.

\section{Discussion}

Seventy four patients in the Sheffield and Rotherham area were receiving long term domiciliary oxygen therapy by means of oxygen concentrators at the time of this survey in 1987. A community survey ${ }^{6}$ estimated that about 600 patients with chronic bronchitis and emphysema in this catchment area of around 550000 would be likely to benefit from long term domiciliary oxygen therapy. The benefits of this treatment in such a population have not been established, but even so many patients who would be eligible are probably not receiving treatment.

Long term domiciliary oxygen therapy is relatively expensive, costing about $£ 1200$ a patient each year. Guidelines for selecting patients were published by the Department of Health and Social Security in an attempt to ensure that only suitable patients are given treatment. ${ }^{3}$ Most of our patients had chronic bronchitis and emphysema with at least one episode of cor pulmonale (fluid retention). These patients had substantial airflow obstruction (mean $\mathrm{FEV}_{1} 0.64$ (SD 0.29) $1 / \mathrm{min}$ ). Only a few patients-four out of 64-had not been oedematous (category 2). The palliation of other forms of hypoxic lung disease (category 3) was an infrequent reason for prescribing long term domiciliary oxygen therapy in our area.

A considerable proportion (57\%) of patients had not been assessed for oxygen therapy as recommended. Some began long term domiciliary oxygen therapy immediately after an exacerbation of chronic bronchitis-perhaps because of the perceived difficulty of sending hypoxic patients home without oxygen. Inadequate assessment of patients for long term domiciliary oxygen therapy has also been reported by groups from Bristol and Bath, Durham, and Liverpool. ${ }^{7-9}$ Only $64 \%$ of the 82 patients in Bristol and Bath ${ }^{7}$ met the DHSS criteria fully and only $51 \%$ of the 61 in Liverpool. ${ }^{9}$

The logistics of supplying long term oxygen therapy appear to have been satisfactory. Oxygen flow rates and the concentrations delivered were usually accurate. At set rates of $31 /$ min or more the machines are not expected to deliver such a high concentration of oxygen. Most patients were achieving a satisfactory $\mathrm{PaO}_{2}$ with oxygen and most were not retaining carbon dioxide to an extent that would be likely to cause symptoms. We have not been able to measure the daily usage of oxygen objectively but $53 \%$ claimed to be having it for at least 15 hours a day. Some patients, however, evidently had little knowledge of the aims of treatment.

There was an apparent improvement in $\mathrm{PaO}_{2}$ of about $1 \mathrm{kPa}$ during the breathing of air after oxygen therapy. The improvement was seen in the subgroup that had been assessed as recommended, which suggests that inappropriate selection was not the explanation. It was also observed in the 19 patients where direct comparison of arterial blood gas tensions during air breathing was possible. Blood was taken from these patients after they had been breathing room air for at least one hour. Sampling errors or insufficient time for oxygen washout are unlikely to explain the difference.

Most patients having long term domiciliary oxygen therapy in our area were under regular review by a chest physican. Other aspects of their management are likely to have improved in addition to the provision of oxygen. Some of the changes that we report may be due to other treatment (bronchodilators, corticosteroids, regular antibiotics). ${ }^{10}$

Only $13 \%$ were still smoking cigarettes, as judged by carboxyhaemoglobin saturations of over $2.5 \%$, the upper $95 \%$ percentile for nonsmokers in our laboratory. The concentrations of carboxyhaemoglobin reported to be associated with regular smoking vary; Turner et al $^{11}$ found values as low as $1 \cdot 7 \%$. This would imply that $51 \%$ were still smoking, but by either criterion smoking would seem to have fallen substantially. Stopping smoking ${ }^{12-14}$ may have contributed to the improvement of $\mathrm{PaO}_{2}$.

Only $33 \%$ of patients at follow up had $\mathrm{a} \mathrm{PaO}_{2}$ of less than $7.3 \mathrm{kPa}$ while breathing air and would be eligible for long term domiciliary oxygen therapy according to present guidelines. In Liverpool ${ }^{8}$ many patients recieving long term domiciliary oxygen therapy had a 
$\mathrm{PaO}_{2}$ of greater than $7 \cdot 3 \mathrm{kPa}$ when reassessed; pretreatment values were not available in that study. Withdrawal of oxygen therapy in selected patients may be possible but careful follow up would be necessary. A prospective clinical trial would be necessary to determine whether this would affect prognosis or lead to relapse.

There is a need for more careful monitoring of long term domiciliary oxygen therapy. This would be best achieved by establishing a regional or national register of patients containing relevant physiological data. Much of the difficulty in selecting patients and ensuring that they are clinically stable would be reduced by regular monitoring. Many patients will be found to have improved and the continued need for oxygen in this group needs to be assessed.

1 Medical Research Council Working Party. Long term domiciliary oxygen therapy in chronic hypoxic cor pulmonale complicating chronic bronchitis and emphysema. Lancet 1981;i:681-6.

2 Nocturnal Oxygen Therapy Group. Continuous or nocturnal oxygen therapy in hypoxemic chronic obstructive lung disease: A clinical trial. Ann Intern Med 1980;93:391-8.

3 Department of Health and Social Security. Introduction of oxygen concentrators to the domiciliary oxygen therapy service. London: Department of Health and Socia Security, 1986. (Publication No FPN 398.)

4 Anonymous. Long-term domiciliary oxygen therapy. Lancet 1985;ii:365-7.

5 Nunn JF. Applied respiratory physiology. 3rd ed. London: Butterworth 1987:264.

6 Williams BT, Nicholl JP. Prevalence of hypoxaemic chronic obstructive lung disease with reference to long-term obstructive lung disease with reference

7 Dilworth JP, Higgs CMB, Jones PA, White RJ. Prescription of oxygen concentrators: adherence to published guidelines. Thorax 1989;44:576-8.

8 McCallion J, Pearce SJ. Oxygen concentrators: which patients are being treated and are the DHSS guidelines being followed? [abstract] Thorax 1988;43:859P

9 Walshaw MJ, Lim R, Evans CC, Hind CRK. Prescription of oxygen concentrators for long term oxygen treatment: reassessment in one district. Br Med J 1988;297:1030-2.

10 Chung KF, Barnes PJ. Respiratory and allergic disease. II. Chronic obstructive airways disease and respiratory infections. Br Med J 1988;296:111-5.

11 Turner JA McM, McNichol MW, Sillett RW. Distribution of carboxyhaemoglobin concentrations in smokers and non-smokers. Thorax 1986;41:25-7.

12 Barend N, Woolcock AJ, Marlin GE. Correlation between the function and structure of the lung in smokers. $A m R e v$

Respir Dis 1979;119:695-705.
13 Michaels R, Sigurdson M, Thurlbeck S, Cherniack R. Elastic recoil of the lung in cigarette smokers: the effect of nebulised bronchodilator and cessation of smoking. $A m$ Rev Respir Dis 1979;119:707-16.

14 Grant IWB. Oxygen in the home. Br Med J 1982;284:417. 